\title{
An Ordering Policy for Deteriorating Items with Time-Dependent Quadratic Demand and Salvage Value under Permissible Delay in Payment
}

\section{Trailokyanath Singh ${ }^{1 *}$, Madan Mohan Muduly², Chittaranjan Mallick³, Rahul Kumar Gupta1, Hadibandhu Pattanayak ${ }^{4}$}

\author{
${ }^{1}$ Department of Mathematics, C. V. Raman College of Engineering, Bhubaneswar, India \\ ${ }^{2}$ Department of Mathematics, CET, Techno Campus, Bhubaneswar, India \\ ${ }^{3}$ Department of Mathematics, Parala Maharaja Engineering College, Berhampur, India \\ ${ }^{4}$ Department of Mathematics, Ravenshaw University, Cuttack, India \\ Email: *trailokyanaths108@gmail.com, bbsrmadan@rediffmail.com, cmallick75@gmail.com,rkg12012@gmail.com, \\ h.pattnayak@gmail.com
}

How to cite this paper: Singh, T., Muduly, M.M., Mallick, C., Gupta, R.K. and Pattanayak, H. (2019) An Ordering Policy for Deteriorating Items with Time-Dependent Quadratic Demand and Salvage Value under Permissible Delay in Payment. American Journal of Operations Research, 9, 201-218. https://doi.org/10.4236/ajor.2019.95013

Received: April 25, 2019

Accepted: August 12, 2019

Published: August 15, 2019

Copyright $\odot 2019$ by author(s) and Scientific Research Publishing Inc. This work is licensed under the Creative Commons Attribution International License (CC BY 4.0).

http://creativecommons.org/licenses/by/4.0/

\section{(c) (i) Open Access}

\begin{abstract}
The article deals with an economic order quantity (EOQ) inventory model for deteriorating items in which the supplier provides the purchaser a permissible delay in payment. This is so when deterioration of units in the inventory is subject to constant deterioration rate, demand rate is quadratic function of time and salvage value is associated with the deteriorated units. Shortages in the system are not allowed to occur. A mathematical formulation is developed when the supplier offers a permissible delay period to the customers under two circumstances: 1) when delay period is less than the cycle of time; and 2) when delay period is greater than the cycle of time. The method is suitable for the items like state-of-the-art aircrafts, super computers, laptops, android mobiles, seasonal items and machines and their spare parts. A solution procedure algorithm is given for finding the optimal order quantity which minimizes the total cost of an inventory system. The article includes numerical examples to support the effectiveness of the developed model. Finally, sensitivity analysis on some parameters on optimal solution is provided.
\end{abstract}

\section{Keywords}

Constant Deterioration Rate, Deteriorating Items, Economic Order Quantity, Permissible Delay in Payment, Salvage Value, Time-Dependent Quadratic Demand Rate 


\section{Introduction}

It is commonly observed that most of the physical goods in which appreciable deterioration can take place when the item in stock undergoes changes or becomes out of fashion and consequently the loss must be taken into account when analyzing the model. Deterioration is a natural process which is defined as change, decay, evaporation, loss of utility or marginal value of the commodity. Thus, to control and maintain the inventory of deteriorating items to satisfy customer's demand or retailer's order is very important in nowadays. Of late, many models have been developed for the control and maintenance of the inventory. Generally, for items like hardware, glassware, steel and toys, the rate of deterioration is too low; and there is little need for considering deterioration of the economic lot-size. But items like seasonal food, vegetables, fruit, blood, fish, meat, radioactive substances, alcohol, chemicals, gasoline, drugs, medicine etc. deteriorate remarkably overtime. In the history, the inventory models for deteriorating items have been continuously modified to become more practicable and realistic. Whitin [1], the earliest researcher, studied the deterioration of fashion goods at the end of a prescribed storage period. The next earliest work was Ghare and Schrader's [2] who developed a simple EOQ (Economic Order Quantity) with constant rate of decay. After Ghare and Schrader's [2] work, many researchers worked on inventory model for deteriorating items assuming the rate of deterioration to be constant and time-dependent. Among the researchers, Covert and Philip [3] and Philip [4] used variable deterioration rate and assumption of constant demand rate and no shortages to formulate the inventory model for deteriorating items. An order-level inventory model for deteriorating items with constant demand rate and constant deterioration rate was presented by Shah and Jaiswal [5]. Donaldson [6] developed the classical EOQ model with time-varying linear demand pattern over a finite horizon of time. Aggarwal [7] presented a note on order-level inventory model for deteriorating items with constant deterioration rate and the constant demand rate. Dave and Patel [8] first presented the inventory model for deteriorating items with a linear increasing demand as time-varying demand and constant deterioration rate with no shortages over a finite horizon. Further, Sachan [9] extended Dave and Patel's [8] model to allow for shortages. An optimal inventory model for deteriorating items with two-staged demand rate and time-proportional deterioration rate and no shortages is studied by Singh et al. [10]. They determined EOQ and suggested optimal solution by considering demand rate as constant in first part of the cycle and linear increasing in the other part. The literature surveys by Nahmias [11], Raafat [12], Goyal and Giri [13], Li et al. [14], Bakker et al. [15] and Janssen et al. [16] cite up-to-date review of the advances made in the field of deteriorating inventory.

Recently, Khanra et al. [17] established an inventory model for deteriorating items with constant deterioration rate and time-dependent quadratic demand rate when delay in payment is permitted. The motivation behind developing an 
EOQ model in the present paper is to introduce salvage value into the deteriorated units. Quadratic demand rate depicts different phases of market demand including accelerated rise or fall in demand. Shortages in this system are not allowed to occur. The model is useful for the demand of items such as state-ofthe-art aircrafts, super computers, laptops, android mobiles, seasonal items and machines and their spare parts and also newly launched fashion goods, seasonal items, cosmetics etc. for which the demand rate accelerates as they are launched into the market and declines when the season ends. The objective of the proposed model is to minimize the total cost by obtaining the optimal cycle time. In addition, the value of optimal ordering quantity of the inventory system is calculated. The necessary and sufficient conditions for the optimal solutions of the model are provided. It is observed that the optimal solution not only exists but also unique. At the end, numerical examples are given to illustrate the results obtained and sensitivity analysis of the effect of the parameters on the decision variables and the total inventory cost is carried out.

The remainder of the paper is arranged as follows: In Section 2, the review of literature is presented. In Sections 3 and 4, the notations and fundamental assumptions are used throughout this paper, respectively. Mathematical model with the necessary and sufficient conditions and algorithms of the solution of the model in order to minimize the total relevant inventory costs are given in Sections 5 and 6, respectively. In Sections 7 and 8, numerical examples and the sensitivity analysis of the various parameters are presented to illustrate the model, respectively. Finally, conclusions are drawn and the future research is pointed out in Section 9.

\section{Literature Review}

Demand is considered as the driving force of the inventory system. Therefore, its role is important for the development of inventory system of deteriorating items. While developing an inventory model, most of the inventory researchers usually consider the time-dependent demand either linear or exponential for the whole cycle. But in real life situations, the time-varying linear or exponential demand pattern seldom occurs because the linear demand pattern represents the uniform change in demand whereas the other indicates the rapid change in demand. Dash et al. [18] studied a model for deteriorating items considering exponential declining demand and time-varying holding cost. The advantage of time-dependent quadratic demand rate is that it shows accelerated growth in demand in mid-season and accelerated decline in demand occurs when the season ends. Accelerated growth and accelerated decline in the demand rate are found to occur in the case of the state-of-the-art aircrafts, supercomputers, laptops, android mobiles and machines and their spare parts and in case of obsolete aircrafts, super computers, laptops, android mobiles and machines and their spare parts, respectively. Demand of items may vary with price or with time or even with the instantaneous state of inventory displayed in the market. So in the recent dec- 
ades, several inventory models were developed for finding the economic replenishment polices with time-dependent demand pattern. Goswami and Chaudhuri [19], Chakrabarti and Chaudhuri [20], Benkherouf [21] etc. have proposed EOQ models for deteriorating items focusing on the time-varying linear demand. The inventory models for deteriorating items with time-varying exponentially demand patterns are also studied by Wee [22] and Jalan and Chaudhuri [23]. But in real life situations, the time-varying linear or exponential demand pattern seldom occurs because the linear demand pattern represents the uniform change in demand whereas the other indicates the rapid change in demand. Khanra and Chaudhuri [24] and Ghosh and Chaudhuri [25] etc. have developed the inventory models taking time-varying quadratic demand rate into consideration. A note on a two-warehouse inventory model for deteriorating items with varying quadratic demand under conditionally permissible delay in payment is proposed by Singh and Pattanayak [26]. Singh and Pattanayak [27] developed an EOQ inventory model for deteriorating items with quadratic demand and partial backlogging with no shortages.

In the conventional EOQ inventory model, the costs of the items are assumed to be paid at the time of delivery by the supplier. However, this assumption is not always suitable for business practices, as the supplier allows credit facilities to attract more customers for business competition situations. Such an advantage is likely to motivate customer to order more quantities because paying later indirectly reduces the purchase cost. In business competitions, the practical scenario for the supplier to survive in the market is to offer customers some grace period enabling them to pay later. The customer does not have to pay any interest during this fixed period, but if the payment gets delayed, the supplier will charge interest for the period. Generally, the credit period in which the suppliers offer to the retailers with interest is known as the trade credit period or permissible delay period or delay period. During this period, he may sell the goods, accumulate revenues on the sales and earn interest on that revenue. In other words, trade credit period is a powerful promotional tool by which suppliers encourage and attract the retailers. Therefore, trade credit plays an important role in inventory control for both the supplier and the customers. In business market, the unit selling price should be greater than the unit purchasing price. Generally, suppliers offer delay period on purchase of items to the retailer. During this period, the retailer is encouraged to buy more items and accumulate revenues by selling items and earning interest. Initially, Goyal [28] studied the economic order quantity with constant demand rate under conditions of permissible delay in payments. Aggarwal and Jaggi [29] studied the ordering policies of deteriorating items with constant demand rate and constant deterioration rate under permissible delay in payments. Among the deterministic demand rates, quadratic demand rate is the most realistic demand rate considered for the development of inventory models for deteriorating items. Khanra et al. [17] established an inventory model for deteriorating items with constant deterioration 
rate and time-dependent quadratic demand rate when delay in payment is permitted. Musa and Sani [30] studied the ordering policies for the inventory model of delayed deteriorating items under permissible delay in payments. Now-a-days, inventory researchers try to develop simple and easy solution procedures for implementation in management science. In this regard, Chen et al. [31] proposed a simple arithmetic-geometric method to solve the inventory problem and established some discrimination terms to identify the unique optimal among three alternatives under conditionally permissible delay in payment. Singh et al. [32] studied an EOQ model for a deteriorating item with initial order quantity demand and inventory dependent deterioration under permissible delay in payment scheme.

Most of the inventory models developed assumed that the deterioration of a unit is a complete loss and that these deteriorated units have no sale value. They are considered as lost. But, in real life situations, the supplier can offer a fixed reduced unit cost to his retailer for the deteriorated stock in order to reduce the total inventory cost. In other words, inclusion of salvage value into the deteriorated stock benefits both the supplier and retailer. The proposed strategy can be implemented in inventory control model of selling seasonal items, fashion items, automobiles, smart phones and machines and their spare parts. In the several articles, the models assumed that deteriorated units have salvage values. So they are considered as lost in business. To overcome such loss, supplier can offer to his retailer reduced unit cost for the deteriorated stocks. In this respect, Jaggi and Aggarwal [33] proposed the concept of inclusion of salvage value into deteriorated units in the inventory model. Later, Mishra and Shah [34] developed the inventory model for time dependent deteriorating items with salvage values. In their paper, the salvage value is associated into the deteriorated units. An optimal policy for deteriorating items with constant demand rate, constant deterioration rate, incorporation of salvage value into the deteriorated items and shortages is studied by Annadurai [35]. Mishra and Tripathy [36] presented an inventory model with constant demand rate and the three-parameter weibull distribution deterioration rate by introducing the salvage value into deteriorated units for the calculation of minimization of total cost.

\section{Fundamental Assumptions}

The following assumptions are needed for developing the mathematical model:

1) The deterioration rate is constant for the period, which is practically very small.

2) A single type of item is considered over a prescribed period.

3) The delivery lead time (i.e., the length of time between making a decision to replenish an item and its actual addition to stock) is zero.

4) Replacement rate occurs instantaneously.

5) The demand rate is known and is a quadratic increasing function of 
time.

6) The planning horizon of the inventory system is infinite.

7) No shortages in inventory are allowed.

8) The supplier offers the purchaser a delay period in paying for purchasing cost and the purchaser can accumulate revenues by selling items and by earning interest.

\section{Model Development}

The paper is developed considering the replenishment problem of a single deteriorating item. The inventory system starts at time $t=0$ when a lot size of a certain number of units enters the system and ends with zero inventory at time $t=T$. The depletion of inventory occurs due to combined effect of the timedependent quadratic demand rate and constant deterioration rate in time period $0 \leq t \leq T$. Thus, the governing differential equation of the instantaneous state of inventory level $I(t)$ at any time $t$ is given by

$$
\frac{\mathrm{d} I(t)}{\mathrm{d} t}+\theta I(t)=-R(t), \quad 0 \leq t \leq T,
$$

with the boundary conditions $I(0)=I_{o}$

and

$$
I(T)=0
$$

where $R(t)=a+b t+c t^{2}$.

The solution of Equation (1) is given by

$$
\begin{aligned}
I(t)= & \left(\frac{a+b T+c T^{2}}{\theta}-\frac{b+2 c T}{\theta^{2}}+\frac{2 c}{\theta^{3}}\right) \mathrm{e}^{\theta(T-t)} \\
& -\frac{a+b t+c t^{2}}{\theta}+\frac{b+2 c t}{\theta^{2}}-\frac{2 c}{\theta^{3}}, \quad 0 \leq t \leq T
\end{aligned}
$$

and the order quantity is

$$
I_{o}=I(0)=\left(\frac{a+b T+c T^{2}}{\theta}-\frac{b+2 c T}{\theta^{2}}+\frac{2 c}{\theta^{3}}\right) \mathrm{e}^{\theta T}-\frac{a}{\theta}+\frac{b}{\theta^{2}}-\frac{2 c}{\theta^{3}}
$$

Now, the model is analyzed under three possibilities depending upon the relationship between delay period and cycle time.

Case A: $t_{p}<T$. (Delay period is less than the cycle time).

The total variable cost comprises the sum of the ordering cost, holding cost, deterioration cost and interest chargeable minus the sum of the salvage value of the deteriorated items and interest earned. They are grouped together after evaluating the above costs individually.

1) The ordering cost $(O C)$ is

$$
O C=C_{3}
$$

2) The deterioration cost $(D C)$ : 
The total demand during the time period $[0, T]$ is

$$
\int_{0}^{T} R(t) \mathrm{d} t=a T+\frac{b T^{2}}{2}+\frac{c T^{3}}{3}
$$

The total number of deteriorated units is given by

$$
\begin{aligned}
I_{0}-\int_{0}^{T} R(t) \mathrm{d} t= & \left(\frac{a+b T+c T^{2}}{\theta}-\frac{b+2 c T}{\theta^{2}}+\frac{2 c}{\theta^{3}}\right) \mathrm{e}^{\theta T} \\
& -\frac{a}{\theta}+\frac{b}{\theta^{2}}-\frac{2 c}{\theta^{3}}-a T-\frac{b T^{2}}{2}-\frac{c T^{3}}{3}
\end{aligned}
$$

Thus, the deterioration cost $(D C)$ for the period $[0, T]$ is

$$
\begin{aligned}
D C= & C_{2}\left[\left(\frac{a+b T+c T^{2}}{\theta}-\frac{b+2 c T}{\theta^{2}}+\frac{2 c}{\theta^{3}}\right) \mathrm{e}^{\theta T}\right. \\
& \left.-\frac{a}{\theta}+\frac{b}{\theta^{2}}-\frac{2 c}{\theta^{3}}-a T-\frac{b T^{2}}{2}-\frac{c T^{3}}{3}\right]
\end{aligned}
$$

3) The salvage value ( $C S V$ ) for deteriorated items for the period $[0, T]$ is

$$
\begin{aligned}
C S V= & \chi\left[\left(\frac{a+b T+c T^{2}}{\theta}-\frac{b+2 c T}{\theta^{2}}+\frac{2 c}{\theta^{3}}\right) \mathrm{e}^{\theta T}\right. \\
& \left.-\frac{a}{\theta}+\frac{b}{\theta^{2}}-\frac{2 c}{\theta^{3}}-a T-\frac{b T^{2}}{2}-\frac{c T^{3}}{3}\right]
\end{aligned}
$$

4) The holding cost ( $H C)$ for the period $[0, T]$ is

$$
\begin{aligned}
H C= & \frac{C_{1}\left(\mathrm{e}^{\theta T}-1\right)}{\theta^{2}}\left(a+b T+c T^{2}-\frac{b+2 c T}{\theta}+\frac{2 c}{\theta^{2}}\right) \\
& -\frac{C_{1} T}{\theta}\left[a+\frac{b T}{2}+\frac{c T^{2}}{3}-\frac{b+c T}{\theta}+\frac{2 c}{\theta^{2}}\right]
\end{aligned}
$$

5) The interest payable $\left(P I_{A}\right)$ for the period $[0, T]$ is

$$
\begin{aligned}
P I_{A}= & \frac{C_{2} I_{c}}{\theta^{2}}\left(\mathrm{e}^{\theta\left(T-t_{p}\right)}-1\right)\left(a+b T+c T^{2}-\frac{b+2 c T}{\theta}+\frac{2 c}{\theta^{2}}\right) \\
& -\frac{C_{2} I_{c}\left(T-t_{p}\right)}{\theta}\left[a+\frac{b\left(T+t_{p}\right)}{2}+\frac{c\left(T^{2}+T t_{p}+t_{p}^{2}\right)}{3}-\frac{b+c\left(T+t_{p}\right)}{\theta}+\frac{2 c}{\theta^{2}}\right]
\end{aligned}
$$

where $C_{1}=h_{1} C_{2}$.

6) The interest earned $\left(E I_{A}\right)$ for the period $[0, T]$ is

$$
E I_{A}=p I_{e} \int_{0}^{T} t R(t) \mathrm{d} t=p I_{e} T^{2}\left(\frac{a}{2}+\frac{b T}{3}+\frac{c T^{2}}{4}\right) .
$$

The total cost function for the period $[0, T]$ is defined as

$$
T C_{A}(T)=O C+H C+(D C-C S V)+P I_{A}-E I_{A} .
$$

The total variable cost per unit time $\left(T V C_{A}(T)\right)$ for the period $[0, T]$ is 


$$
\begin{aligned}
T V C_{A}(T)= & \frac{1}{T}\left[O C+H C+(D C-C S V)+P I_{A}-E I_{A}\right] \\
= & \frac{C_{3}}{T}+\frac{C_{1}}{\theta T}\left[\left(a+b T+c T^{2}-\frac{b+2 c T}{\theta}+\frac{2 c}{\theta^{2}}\right)\left(\frac{\mathrm{e}^{\theta T}-1}{\theta}\right)\right. \\
& \left.-a T-\frac{b T^{2}}{2}-\frac{c T^{3}}{3}+\frac{b T+c T^{2}}{\theta}-\frac{2 c T}{\theta^{2}}\right] \\
& +\frac{\left(C_{2}-\chi\right)}{T}\left[\left(\frac{a+b T+c T^{2}}{\theta}-\frac{b+2 c T}{\theta^{2}}+\frac{2 c}{\theta^{3}}\right) \mathrm{e}^{\theta T}\right. \\
& \left.-\frac{a}{\theta}+\frac{b}{\theta^{2}}-\frac{2 c}{\theta^{3}}-a T-\frac{b T^{2}}{2}-\frac{c T^{3}}{3}\right] \\
& +\frac{C_{2} I_{c}}{\theta T}\left(a+b T+c T^{2}-\frac{b+2 c T}{\theta}+\frac{2 c}{\theta^{2}}\right)\left(\frac{\mathrm{e}^{\theta\left(T-t_{p}\right)}-1}{\theta}\right) \\
& -C_{2} I_{e} T\left(\frac{a}{2}+\frac{b T}{3}+\frac{c T^{2}}{4}\right)-\frac{C_{2} I_{c}\left(T-t_{p}\right)}{\theta T}\left[a+\frac{b\left(T+t_{p}\right)}{2}\right. \\
& \left.+\frac{c\left(T^{2}+T t_{p}+t_{p}^{2}\right)}{3}-\frac{b+c\left(T+t_{p}\right)}{\theta}+\frac{2 c}{\theta^{2}}\right]
\end{aligned}
$$

The objective of the problem is to determine the optimal value of $T$ so that $T V C(T)$ is minimized. The necessary condition to minimize $T V C_{A}(T)$ for a given value of $t_{p}$ is

$$
\frac{\mathrm{d}\left[T V C_{A}(T)\right]}{\mathrm{d} T}=0
$$

provided it satisfies the condition $\frac{\mathrm{d}^{2}\left[T V C_{A}(T)\right]}{\mathrm{d} T^{2}}>0$.

From Equation (14), the respective non-linear equation is

$$
\begin{aligned}
& \frac{\mathrm{d}\left[T V C_{A}(T)\right]}{\mathrm{d} T} \\
& =\left(a+b T+c T^{2}\right)\left[\left(\frac{C_{1}}{\theta}+C_{2}-\chi\right)\left(\mathrm{e}^{\theta T}-1\right)+\frac{C_{2} I_{c}}{\theta}\left(\mathrm{e}^{\theta\left(T-t_{p}\right)}-1\right)-C_{2} I_{e} T\right] \\
& -\left[T V C_{A}(T)\right] \\
& =0
\end{aligned}
$$

The second order of $T V C_{A}(T)$ with respect to $T$ is as follows:

$$
\begin{aligned}
& \frac{\mathrm{d}^{2}\left[T V C_{A}(T)\right]}{\mathrm{d} T^{2}} \\
= & \frac{\left(a+b T+c T^{2}\right)}{T}\left[\left(\frac{C_{1}}{\theta}+C_{2}-\chi\right) \theta \mathrm{e}^{\theta T}+C_{2} I_{c} \mathrm{e}^{\theta\left(T-t_{p}\right)}-C_{2} I_{e}\right] \\
& -\frac{(2 a+b T)}{T^{2}}\left[\left(\frac{C_{1}}{\theta}+C_{2}-\chi\right)\left(\mathrm{e}^{\theta T}-1\right)+\frac{C_{2} I_{c}}{\theta}\left(\mathrm{e}^{\theta\left(T-t_{p}\right)}-1\right)-C_{2} I_{e} T\right] \\
& +\frac{2}{T^{2}}\left[T V C_{A}(T)\right]
\end{aligned}
$$


Case B: $t_{p}>T$. (Delay period is greater than the cycle time)

Here, total variable cost comprises the sum of the ordering cost, holding cost and deterioration cost interest chargeable minus the sum of the salvage value of the deteriorated items and interest earned as interest chargeable is zero. The ordering cost, holding cost, deterioration cost and the salvage value of the deteriorated items are same as Case A.

Now, the total interest earned $\left(E I_{B}\right)$ during the cycle time is given by the sum of the interest earned during the period $[0, T]$ and the interest earned during the delay period $\left[T, t_{p}\right]$. Thus,

$$
\begin{aligned}
E I_{B} & =C_{2} I_{e} \int_{0}^{T} t R(t) \mathrm{d} t+C_{2} I_{e}\left(t_{p}-T\right) \int_{0}^{T} R(t) \mathrm{d} t \\
& =C_{2} I_{e} T\left[\left(a+\frac{b T}{2}+\frac{c T^{2}}{3}\right) t_{p}-\frac{a T}{2}-\frac{b T^{2}}{6}-\frac{c T^{3}}{12}\right]
\end{aligned}
$$

Here, the total cost function in this case is defined as

$$
T C_{B}(T)=O C+H C+(D C-C S V)-E I_{B}
$$

The total variable cost per unit time $\left(T V C_{B}(T)\right)$ in this case is

$$
\begin{aligned}
T V C_{B}(T)= & \frac{1}{T}\left[O C+H C+(D C-C S V)-E I_{B}\right] \\
= & \frac{C_{3}}{T}+\frac{C_{1}}{\theta T}\left[\left(a+b T+c T^{2}-\frac{b+2 c T}{\theta}+\frac{2 c}{\theta^{2}}\right)\left(\frac{\mathrm{e}^{\theta T}-1}{\theta}\right)-a T\right. \\
& \left.-\frac{b T^{2}}{2}-\frac{c T^{3}}{3}+\frac{b T+c T^{2}}{\theta}-\frac{2 c T}{\theta^{2}}\right] \\
& +\frac{\left(C_{2}-\chi\right)}{T}\left[\left(\frac{a+b T+c T^{2}}{\theta}-\frac{b+2 c T}{\theta^{2}}+\frac{2 c}{\theta^{3}}\right) \mathrm{e}^{\theta T}\right. \\
& \left.-\frac{a}{\theta}+\frac{b}{\theta^{2}}-\frac{2 c}{\theta^{3}}-a T-\frac{b T^{2}}{2}-\frac{c T^{3}}{3}\right] \\
& -C_{2} I_{e}\left[\left(a+\frac{b T}{2}+\frac{c T^{2}}{3}\right) t_{p}-\frac{a T}{2}-\frac{b T^{2}}{6}-\frac{c T^{3}}{12}\right]
\end{aligned}
$$

The necessary condition to minimize $T V C_{B}(T)$ for a given value of $t_{p}$ is

$$
\frac{\mathrm{d}\left[T V C_{B}(T)\right]}{\mathrm{d} T}=0
$$

provided it satisfies the condition $\frac{\mathrm{d}^{2}\left[T V C_{B}(T)\right]}{\mathrm{d} T^{2}}>0$.

From (20), the respective non-linear equation is

$$
\begin{aligned}
& \frac{\mathrm{d}\left[T V C_{B}(T)\right]}{\mathrm{d} T} \\
= & \left(a+b T+c T^{2}\right)\left(\mathrm{e}^{\theta T}-1\right)\left(\frac{C_{1}}{\theta}+C_{2}-\chi\right) \\
& -C_{2} I_{e}\left[t_{p}\left(a+b T+c T^{2}\right)-a T-\frac{b T^{2}}{2}-\frac{c T^{3}}{3}\right]-\left[T V C_{B}(T)\right] \\
= & 0
\end{aligned}
$$


The second order derivative of $T V C_{B}(T)$ with respect to $T$ is as follows:

$$
\begin{aligned}
& \frac{\mathrm{d}^{2}\left[T V C_{B}(T)\right]}{\mathrm{d} T^{2}} \\
= & \frac{\left(a+b T+c T^{2}\right)}{T}\left[\left(\frac{C_{1}}{\theta}+C_{2}-\chi\right) \theta \mathrm{e}^{\theta T}+C_{2} I_{c} \mathrm{e}^{\theta\left(T-t_{p}\right)}-C_{2} I_{e}\right] \\
& -\frac{(2 a+b T)}{T^{2}}\left[\left(\frac{C_{1}}{\theta}+C_{2}-\chi\right)\left(\mathrm{e}^{\theta T}-1\right)+\frac{C_{2} I_{c}}{\theta}\left(\mathrm{e}^{\theta\left(T-t_{p}\right)}-1\right)-C_{2} I_{e}\right] \\
& +\frac{2}{T^{2}}\left[T V C_{B}(T)\right]
\end{aligned}
$$

Case C: $t_{p}=T$. (Delay period is equal to the cycle time).

The respective cost function is obtained from either Equation (13) or Equation (19) by substituting $T=t_{p}$ because of both of $\left(T V C_{A}(T)\right)$ and $\left(T V C_{B}(T)\right)$ are identical.

Based on the results above, a procedure is derived to locate the optimal cycle time for the two cases.

\section{Solution Procedure}

The following Solution procedure is recommended for the calculation of EOQ and optimal solution.

Step I: Perform (1)-(9).

1) Assign values to the parameters.

2) Solve equation (15) for $T_{1}^{*}$.

3) Test the respective sufficient condition.

4) Compare $T_{1}^{*}$ with $t_{p}$.

5) If $T_{1}^{*}>t_{p}$, then substitute the value of $T_{1}^{*}$ in Equation (13) to get $T V C_{A}\left(T_{1}^{*}\right)$.

6) Solve Equation (21) for $T_{2}^{*}$.

7) Test the respective sufficient condition.

8) Compare $T_{2}^{*}$ with $t_{p}$.

9) If $T_{2}^{*}<t_{p}$, then substitute the value of $T_{2}^{*}$ in Equation (19) to get $T V C_{B}\left(T_{2}^{*}\right)$.

Then the following decision will be held.

Decision I. If $T_{1}^{*}>t_{p}>T_{2}^{*}$ is satisfied, then the optimal cost $\operatorname{TVC}\left(T^{*}\right)$, i.e., the minimum cost is obtained by comparing both $T V C_{A}\left(T_{1}^{*}\right)$ and $T V C_{B}\left(T_{2}^{*}\right)$ and evaluate the corresponding optimal order quantity $I_{o}^{*}$ from Equation (3).

Step II: Decision II. If $T_{1}^{*}>t_{p}$ and $T_{2}^{*}>t_{p}$ are satisfied, then the optimal cost $\operatorname{TVC}\left(T^{*}\right)$ is $\operatorname{TVC}_{A}\left(T_{1}^{*}\right)$ and evaluate the corresponding optimal order quantity $I_{o}^{*}$ from Equation (3).

Decision III. If $T_{1}^{*}<t_{p}$ and $T_{2}^{*}<t_{p}$ are satisfied, then the optimal cost $\operatorname{TVC}\left(T^{*}\right)$ is $T V C_{B}\left(T_{2}^{*}\right)$ and evaluate the corresponding optimal order quantity $I_{o}^{*}$ from Equation (3).

The following numerical examples are presented in order to demonstrate the 
above solution procedure which can be applied to determine the optimal solution.

\section{Numerical Examples}

Example 1. (Case A and Case B): Minimum average cost is $\operatorname{TVC}_{A}\left(T_{1}^{*}\right)$.

Let $a=1000, b=150, c=15, \theta=0.20, C_{1}=0.12, C_{2}=20, C_{3}=200$, $\chi=0.02, I_{c}=0.15, I_{e}=0.13$, and $t_{p}=0.25$ in appropriate units. Solving Equation (13), we get $T_{1}^{*}=0.351257$ year and putting $T_{1}^{*}=0.351257$ year in Equation (13), the corresponding average cost is $T V C_{A}\left(T_{1}^{*}\right)=\$ 939.98$ which satisfies the sufficient condition (16), i.e., $\frac{\mathrm{d}^{2}\left[T V C_{A}\left(T_{1}^{*}\right)\right]}{\mathrm{d} T^{2}}=15048.8>0$.

Similarly, solving Equation (21), we get $T_{2}^{*}=0.238718$ year and putting $T_{2}^{*}=0.238718$ year in Equation (19), the corresponding average cost is $\operatorname{TVC}_{B}\left(T_{2}^{*}\right)=\$ 1001.42$ which satisfies the sufficient condition (22), i.e., $\frac{\mathrm{d}^{2}\left[T V C_{B}\left(T_{2}^{*}\right)\right]}{\mathrm{d} T^{2}}=30273.846>0$.

In this case, by Step I, the optimal average cost is $T V C_{A}\left(T_{1}^{*}\right)=\$ 939.98$ and the corresponding cycle length is $T_{1}^{*}=0.351257$ year and the corresponding EOQ is $I_{o}^{*}\left(T_{1}^{*}\right)=373.846$.

Example 2. (Case A and B): Minimum average cost is $T V C_{B}\left(T_{2}^{*}\right)$.

Let $a=1000, b=150, c=15, \theta=0.20, C_{1}=0.12, C_{2}=20, C_{3}=200$, $\chi=0.02, I_{c}=0.15, I_{e}=0.13$ and $t_{p}=0.35$ in appropriate units. Solving Equation (15), we get $T_{1}^{*}=0.401514$ year and putting $T_{1}^{*}=0.401514$ year in Equation (13), the corresponding average cost is $T V C_{A}\left(T_{1}^{*}\right)=\$ 884.336$ which satisfies the sufficient condition (16), i.e., $\frac{\mathrm{d}^{2}\left[T V C_{A}\left(T_{1}^{*}\right)\right]}{\mathrm{d} T^{2}}=13280.9>0$.

Similarly, solving Equation (21), we get $T_{2}^{*}=0.239385$ year and putting $T_{2}^{*}=0.239385$ year in Equation (19), the corresponding average cost is $T V C_{B}\left(T_{2}^{*}\right)=\$ 736.681$ which satisfies the sufficient condition (22), i.e., $\frac{\mathrm{d}^{2}\left[T V C_{B}\left(T_{2}^{*}\right)\right]}{\mathrm{d} T^{2}}=30026.2>0$.

In this case, by Step I, the optimal average cost is $T V C_{B}\left(T_{2}^{*}\right)=\$ 736.681$ and the corresponding cycle length is $T_{2}^{*}=0.239385$ year and the corresponding EOQ is $I_{o}^{*}\left(T_{2}^{*}\right)=249.717$.

\section{Sensitivity Analysis}

The effect of changing of the several parameters on the optimal cycle time and the optimal total cost is studied. The sensitivity analysis of the parameters present in this model is also performed. The optimal values of the total average cost $\operatorname{TVC}\left(T^{*}\right)$ change significantly with changes $(-50 \%,-25 \%,-10 \%,+10 \%$, $+25 \%,+50 \%)$ of different parameters value in Table 1 based on Example 1 .

On the basis of sensitivity analysis of the parameters, the following features 
Table 1. Effect of changes in the parameters of the inventory.

\begin{tabular}{|c|c|c|c|c|c|c|c|}
\hline $\begin{array}{l}\text { Changing } \\
\text { parameters }\end{array}$ & $\begin{array}{l}\text { Change in } \\
\text { parameters }\end{array}$ & $\begin{array}{c}\text { Cycle length } \\
\qquad\left(T_{1}^{*}\right)\end{array}$ & $\begin{array}{c}\text { Total cost } \\
\left(T V C_{A}\left(T_{1}^{*}\right)\right)\end{array}$ & $\begin{array}{l}\text { Cycle length } \\
\qquad\left(T_{2}^{*}\right)\end{array}$ & $\begin{array}{c}\text { Total cost } \\
\left(T V C_{B}\left(T_{2}^{*}\right)\right)\end{array}$ & $\begin{array}{l}\text { Optimal cycle } \\
\text { length }\left(T^{*}\right)\end{array}$ & $\begin{array}{l}\text { Optimal total cost } \\
\quad\left(T V C\left(T^{*}\right)\right)\end{array}$ \\
\hline \multirow{6}{*}{$a$} & +50 & 0.311248 & 1079.73 & 0.196504 & 1041.62 & 0.196504 & 1041.62 \\
\hline & +25 & 0.328076 & 1012.97 & 0.214591 & 1030.43 & 0.214591 & 1030.43 \\
\hline & +10 & 0.341003 & 970.087 & 0.228140 & 1015.52 & 0.228140 & 1015.52 \\
\hline & -10 & 0.363206 & 908.398 & 0.250887 & 983.430 & 0.363206 & 908.398 \\
\hline & -25 & 0.385391 & 857.595 & 0.273124 & 947.763 & 0.385391 & 857.595 \\
\hline & -50 & 0.441043 & 759.892 & 0.327654 & 856.993 & 0.441043 & 759.892 \\
\hline \multirow{6}{*}{$b$} & +50 & 0.347954 & 945.380 & 0.237367 & 1003.39 & 0.347954 & 945.380 \\
\hline & +25 & 0.349579 & 942.696 & 0.238036 & 1002.41 & 0.349579 & 942.696 \\
\hline & +10 & 0.350579 & 941.070 & 0.238444 & 1001.82 & 0.350579 & 941.070 \\
\hline & -10 & 0.351943 & 938.885 & 0.238994 & 1001.01 & 0.351943 & 938.885 \\
\hline & -25 & 0.352989 & 937.232 & 0.239411 & 1000.41 & 0.352989 & 937.232 \\
\hline & -50 & 0.354780 & 934.451 & 0.240117 & 999.384 & 0.354780 & 934.451 \\
\hline \multirow{6}{*}{$c$} & +50 & 0.354369 & 957.299 & 0.238689 & 1001.45 & 0.354369 & 957.299 \\
\hline & +25 & 0.352804 & 948.581 & 0.238704 & 1001.43 & 0.352804 & 948.581 \\
\hline & +10 & 0.351873 & 943.406 & 0.238712 & 1001.42 & 0.351873 & 943.406 \\
\hline & -10 & 0.350643 & 936.572 & 0.238723 & 1001.41 & 0.350643 & 936.572 \\
\hline & -25 & 0.349727 & 931.494 & 0.238732 & 1001.40 & 0.349727 & 931.494 \\
\hline & -50 & 0.348215 & 923.120 & 0.238746 & 1001.38 & 0.348215 & 923.120 \\
\hline \multirow{6}{*}{$\theta$} & +50 & 0.288355 & 1261.25 & 0.208512 & 1237.54 & 0.288355 & 1261.25 \\
\hline & +25 & 0.314936 & 1104.92 & 0.222126 & 1123.26 & 0.314936 & 1104.92 \\
\hline & +10 & 0.335154 & 1006.81 & 0.231656 & 1051.16 & 0.335154 & 1006.81 \\
\hline & -10 & 0.370299 & 872.666 & 0.246449 & 950.183 & 0.370299 & 872.666 \\
\hline & -25 & 0.407349 & 774.140 & 0.259560 & 870.214 & 0.407349 & 774.140 \\
\hline & -50 & 0.528423 & 674.344 & 0.286847 & 727.005 & 0.528423 & 674.344 \\
\hline \multirow{6}{*}{$C_{1}$} & +50 & 0.351931 & 966.618 & 0.237652 & 1008.85 & 0.351931 & 966.618 \\
\hline & +25 & 0.351593 & 953.285 & 0.238183 & 1005.14 & 0.351593 & 953.285 \\
\hline & +10 & 0.351391 & 945.299 & 0.238503 & 1002.91 & 0.351391 & 945.299 \\
\hline & -10 & 0.351122 & 934.666 & 0.238933 & 999.925 & 0.351122 & 934.666 \\
\hline & -25 & 0.350902 & 926.703 & 0.239256 & 997.685 & 0.350902 & 926.703 \\
\hline & -50 & 0.350585 & 913.455 & 0.239798 & 993.945 & 0.350585 & 913.455 \\
\hline \multirow{6}{*}{$\mathrm{C}_{2}$} & +50 & 0.310932 & 1047.57 & 0.196518 & 1036.24 & 0.196518 & 1036.24 \\
\hline & +25 & 0.327754 & 1010.45 & 0.214539 & 1027.76 & 0.327754 & 1010.45 \\
\hline & +10 & 0.340807 & 969.102 & 0.228094 & 1014.46 & 0.340807 & 969.102 \\
\hline & -10 & 0.363554 & 909.325 & 0.250998 & 984.432 & 0.363554 & 909.325 \\
\hline & -25 & 0.386787 & 859.717 & 0.273639 & 950.069 & 0.386787 & 859.717 \\
\hline & -50 & 0.448166 & 762.779 & 0.330790 & 859.988 & 0.448166 & 762.779 \\
\hline
\end{tabular}




\begin{tabular}{|c|c|c|c|c|c|c|c|}
\hline \multirow{6}{*}{$C_{3}$} & +50 & 0.402373 & 1214.36 & 0.290496 & 1379.22 & 0.402373 & 1214.36 \\
\hline & +25 & 0.377880 & 1081.84 & 0.265993 & 1199.53 & 0.377880 & 1081.84 \\
\hline & +10 & 0.362194 & 997.984 & 0.250019 & 1083.26 & 0.362194 & 997.984 \\
\hline & -10 & 0.339889 & 880.094 & 0.226802 & 915.493 & 0.339889 & 880.094 \\
\hline & -25 & 0.321920 & 786.265 & 0.207535 & 777.356 & 0.207535 & 777.356 \\
\hline & -50 & 0.288966 & 616.802 & 0.170235 & 512.707 & 0.170235 & 512.707 \\
\hline \multirow{6}{*}{$\chi$} & +50 & 0.351334 & 939.621 & 0.238753 & 1001.17 & 0.351334 & 939.621 \\
\hline & +25 & 0.351215 & 939.801 & 0.238736 & 1001.29 & 0.351215 & 939.801 \\
\hline & +10 & 0.351272 & 939.908 & 0.238725 & 1001.37 & 0.351272 & 939.908 \\
\hline & -10 & 0.351241 & 940.052 & 0.238711 & 1001.47 & 0.351241 & 940.052 \\
\hline & -25 & 0.351218 & 940.160 & 0.238700 & 1001.54 & 0.351218 & 940.160 \\
\hline & -50 & 0.351179 & 940.339 & 0.238682 & 1001.66 & 0.351179 & 940.339 \\
\hline \multirow{6}{*}{$I_{c}$} & +50 & 0.329930 & 955.000 & 0.238718 & 1001.42 & 0.329930 & 955.000 \\
\hline & +25 & 0.339316 & 948.231 & 0.238718 & 1001.42 & 0.339316 & 948.231 \\
\hline & +10 & 0.346109 & 943.489 & 0.238718 & 1001.42 & 0.346109 & 943.489 \\
\hline & -10 & 0.357000 & 936.148 & 0.238718 & 1001.42 & 0.357000 & 936.148 \\
\hline & -25 & 0.366988 & 929.687 & 0.238718 & 1001.42 & 0.366988 & 929.687 \\
\hline & -50 & 0.388717 & 916.463 & 0.238718 & 1001.42 & 0.388717 & 916.463 \\
\hline \multirow{6}{*}{$I_{e}$} & +50 & 0.411444 & 694.678 & 0.219984 & 821.307 & 0.411444 & 694.678 \\
\hline & +25 & 0.377918 & 821.947 & 0.228784 & 921.857 & 0.377918 & 821.947 \\
\hline & +10 & 0.361248 & 893.754 & 0.234593 & 966.376 & 0.361248 & 893.754 \\
\hline & -10 & 0.342033 & 985.006 & 0.243064 & 1035.91 & 0.342033 & 985.006 \\
\hline & -25 & 0.329441 & 1050.48 & 0.250046 & 1086.58 & 0.329441 & 1050.48 \\
\hline & -50 & 0.311183 & 1154.69 & 0.263125 & 1167.84 & 0.311183 & 1154.69 \\
\hline \multirow{6}{*}{$t_{p}$} & +50 & 0.415372 & 877.827 & 0.239553 & 670.495 & 0.239553 & 670.495 \\
\hline & +25 & 0.381666 & 899.200 & 0.239134 & 835.958 & 0.239134 & 835.958 \\
\hline & +10 & 0.362924 & 921.031 & 0.238884 & 935.234 & 0.362924 & 921.031 \\
\hline & -10 & 0.340300 & 962.853 & 0.238552 & 1067.60 & 0.340300 & 962.853 \\
\hline & -25 & 0.325361 & 1005.35 & 0.238303 & 1166.87 & 0.325361 & 1005.35 \\
\hline & -50 & 0.305092 & 1101.34 & 0.237891 & 1332.32 & 0.305092 & 1101.34 \\
\hline
\end{tabular}

are observed.

1) If the initial rate of demand (a) increases, then the optimal cycle length $\left(T^{*}\right)$ decreases and the optimal average cost $\left(T V C\left(T^{*}\right)\right)$ increases. Here $T^{*}$ and $\operatorname{TVC}\left(T^{*}\right)$ are moderately sensitive to change in $a$.

2) If the rate of increasing demand $(b)$ increases, then the optimal cycle length $\left(T^{*}\right)$ decreases and the optimal average cost $\left(T V C\left(T^{*}\right)\right)$ increases. Here $T^{*}$ and $\operatorname{TVC}\left(T^{*}\right)$ are lowly sensitive to change in $b$. 
3) If the rate of changing demand (c) increases, then both the optimal cycle length $\left(T^{*}\right)$ and the optimal average cost $\left(T V C\left(T^{*}\right)\right)$ increase. Here $T^{*}$ and $\operatorname{TVC}\left(T^{*}\right)$ are lowly sensitive to change in $c$.

4) If the rate of deterioration $(\theta)$ increases, then the optimal cycle length $\left(T^{*}\right)$ decreases and the optimal average cost $\left(T V C\left(T^{*}\right)\right)$ increases. Here $T^{*}$ and $\operatorname{TVC}\left(T^{*}\right)$ are highly sensitive to change in $\theta$.

5) If the holding cost per unit time $\left(C_{1}\right)$ increases, then both the optimal cycle length $\left(T^{*}\right)$ and the optimal average cost $\left(T V C\left(T^{*}\right)\right)$ increase. Here $T^{*}$ and $\operatorname{TVC}\left(T^{*}\right)$ are lowly sensitive to change in $C_{1}$.

6) If the unit purchase cost $\left(C_{2}\right)$ increases, then the optimal cycle length $\left(T^{*}\right)$ decreases and the optimal average cost $\left(T V C\left(T^{*}\right)\right)$ increases. Here $T^{*}$ and $\operatorname{TVC}\left(T^{*}\right)$ are highly sensitive to change in $C_{2}$.

7) If the ordering cost $\left(C_{3}\right)$ increases, then both the optimal cycle length $\left(T^{*}\right)$ and the optimal average cost $\left(T V C\left(T^{*}\right)\right)$ increase. Here $T^{*}$ and $T V C\left(T^{*}\right)$ are highly sensitive to change in $C_{3}$.

8) If the salvage value $(\chi)$ increases, then the optimal cycle length $\left(T^{*}\right)$ increases and the optimal average cost $\left(T V C\left(T^{*}\right)\right)$ decreases. Here $T^{*}$ and $\operatorname{TVC}\left(T^{*}\right)$ are lowly sensitive to change in $\chi$.

9) If the interest charged per unit $\left(I_{c}\right)$ increases, then the optimal cycle length $\left(T^{*}\right)$ decreases and the optimal average cost $\left(T V C\left(T^{*}\right)\right)$ increases. Here $T^{*}$ and $\operatorname{TVC}\left(T^{*}\right)$ are lowly sensitive to change in $I_{c}$.

10) If the interest earned per unit $\left(I_{e}\right)$ increases, then the optimal cycle length $\left(T^{*}\right)$ increases and the optimal average cost $\left(T V C\left(T^{*}\right)\right)$ decreases. Here $T^{*}$ and $\operatorname{TVC}\left(T^{*}\right)$ are highly sensitive to change in $I_{e}$.

11) If the permissible delay period $\left(t_{p}\right)$ increases, then both the optimal cycle length $\left(T^{*}\right)$ and the optimal average cost $\left(\operatorname{TVC}\left(T^{*}\right)\right)$ decrease. Here $T^{*}$ and $\operatorname{TVC}\left(T^{*}\right)$ are highly sensitive to change in $t_{p}$.

\section{Conclusions}

The proposed model assumes an EOQ model for deteriorating items with the time-dependent quadratic increasing demand under permissible delay in payment. The reason for considering quadratic demand rate is that it depicts different phases of market demand including accelerated rise or fall in demand. Shortages are not permitted in this inventory system. Salvage value is included in the deteriorated units. The model is suitable for the demand of items such as state-of-the-art aircrafts, super computers, laptops, android mobiles, seasonal items and machines and their spare parts and also newly launched fashion goods, seasonal items, cosmetics etc. for which the demand rate accelerates as they are launched into the market and declines when the season ends. The objective of the model is to optimize the cycle time, ordering cost and the total system costs. Further, several numerical examples and sensitivity analysis with respect to various parameters are presented to validate the theoretical results.

In the future study, it is hoped to extend and incorporate the proposed model 
into several situations, such as, varying deterioration rate like Weibull distribution and Gamma distribution. Also, we could generalize the model to incorporate quantity discounts, inflation rates and allow for shortages and partial backlogging and other things. The present idea can be extended to consider the parameter as fuzzy or stochastic fuzzy. In addition, we could extend the deterministic demand to stochastic fluctuating demand patterns.

\section{Acknowledgements}

The authors would like to express deep felt gratitude to the Editor-in-Chief and the referees for their invaluable suggestions and guidance.

\section{Conflicts of Interest}

The authors declare no conflicts of interest regarding the publication of this paper.

\section{References}

[1] Whitin, T.M. (1957) Theory of Inventory Management. Princeton University Press, Princeton, 62-72.

[2] Ghare, P.M. and Schrader, G.F. (1963) A Model for Exponentially Decaying Inventories. The Journal of Industrial Engineering, 15, 238-243.

[3] Covert, R.P. and Philip, G.C. (1973) An EOQ Model for Items with Weibull Distribution Deterioration. AIIE Transactions, 5, 323-326. https://doi.org/10.1080/05695557308974918

[4] Philip, G.C. (1974) A Generalized EOQ Model for Items with Weibull Distribution Deterioration. AIIE Transaction, 6, 159-162. https://doi.org/10.1080/05695557408974948

[5] Shah, Y.K. and Jaiswal, M.C. (1977) An Order-Level Inventory Model for a System with Constant Rate of Deterioration. OPSEARCH, 14, 174-184.

[6] Donaldson, W.A. (1997) Inventory Replenishment Policy for a Linear Trend in Demand-An Analytical Solution. Operational Research Quarterly, 28, 663-670. https://doi.org/10.1057/jors.1977.142

[7] Aggarwal, S.P. (1978) A Note on an Order-Level Inventory Model for a System with Constant Rate of Deterioration. OPSEARCH, 15, 184-187.

[8] Dave, U. and Patel, L.K. (1981) (T, Si) Policy Inventory Model for Deteriorating Items with Time Proportional Demand. Journal of the Operational Research Society, 32, 137-142. https://doi.org/10.1057/jors.1981.27

[9] Sachan, R.S. (1984) On (T, Si) Inventory Policy Model for Deteriorating Items with Time Proportional Demand. Journal of the Operational Research Society, 35, 1013 1019. https://doi.org/10.1057/jors.1984.197

[10] Singh, T., Mishra, P.J. and Pattanayak, H. (2017) An Optimal Policy for Deteriorating Items with Time-Proportional Deterioration Rate and Constant and Time-Dependent Linear Demand Rate. Journal of Industrial Engineering International, 13, 455-463. https://doi.org/10.1007/s40092-017-0198-6

[11] Nahmias, S. (1982) Perishable Inventory Theory: A Review. Operations Research, 30, 680-708. https://doi.org/10.1287/opre.30.4.680

[12] Rafat, F. (1991) Survey of Literature on Continuously Deteriorating Inventory 
Model. European Journal of Operational Research Society, 42, 27-37. https://doi.org/10.1057/jors.1991.4

[13] Goyal, S.K. and Giri, B.C. (2001) Recent Trends in Modeling of Deteriorating Inventory. European Journal of Operational Research, 134, 1-16. https://doi.org/10.1016/S0377-2217(00)00248-4

[14] Li, R., Lan, H. and Mawhinney, J.R. (2010) A Review on Inventory Study. Journal of Service Science and Management, 3, 117-129. https://doi.org/10.4236/jssm.2010.31015

[15] Bakker, M., Riezebos, J. and Teunter, R.H. (2012) Review of Inventory Systems with Deterioration since 2001. European Journal of Operational Research, 221, 275-284. https://doi.org/10.1016/j.ejor.2012.03.004

[16] Janssen, L., Claus, T. and Sauer, J. (2016) Literature Review of Deteriorating Inventory Models by Key Topics from 2012 to 2015. International Journal of Production Economics, 182, 86-112. https://doi.org/10.1016/j.ijpe.2016.08.019

[17] Khanra, S., Ghosh, S.K. and Chaudhuri, K.S. (2011) An EOQ Model for a Deteriorating Item with Time Dependent Quadratic Demand under Permissible Delay in Payment. Applied Mathematics and Computation, 218, 1-9. https://doi.org/10.1016/j.amc.2011.04.062

[18] Dash, B.P., Singh, T. and Pattanayak, H. (2014) An Inventory Model for Deteriorating Items with Exponential Declining Demand and Time-Varying Holding Cost. American Journal of Operations Research, 4, 1-7. https://doi.org/10.4236/ajor.2014.41001

[19] Goswami, A. and Chaudhuri, K.S. (1991) An EOQ Model for Deteriorating Items with Shortages and a Linear Trend in Demand. Journal of the Operational Research Society, 42, 1105-1110. https://doi.org/10.1057/jors.1991.204

[20] Chakrabarti, T. and Chaudhuri, K.S. (1997) An EOQ Model for Deteriorating Items with Linear Trend in Demand and Shortages in All Cycle. International Journal of Production Economics, 49, 205-213. https://doi.org/10.1016/S0925-5273(96)00015-1

[21] Benkherouf, L. (1995) On an Inventory Model with Deteriorating Items and Decreasing Time-Varying Demand and Shortages. European Journal of the Operational Research, 86, 293-299. https://doi.org/10.1016/0377-2217(94)00101-H

[22] Wee, H.M. (1995) A Deterministic Lot-Size Inventory Model for Deteriorating Items with Shortages and a Declining Market. Computer and Operations Research Society, 22, 345-356. https://doi.org/10.1016/0305-0548(94)E0005-R

[23] Jalan, A.K. and Chaudhuri, K.S. (1999) An EOQ Model for Deteriorating Items in a Declining Market with SFY Policy. Korean Journal of Computational and Applied Mathematics, 6, 437-449.

[24] Khanra, S. and Chaudhuri, K.S. (2003) A Note on an Order Level Inventory for a Deteriorating Item with Time Dependent Quadratic Demand. Computers Operation Research, 30, 1901-1916. https://doi.org/10.1016/S0305-0548(02)00113-2

[25] Ghosh, S.K. and Chaudhuri, K.S. (2006) An EOQ Model with a Quadratic Demand, Time-Proportional Deterioration and Shortages in All Cycles. International Journal of System Sciences, 37, 663-672. https://doi.org/10.1080/00207720600568145

[26] Singh, T. and Pattanayak, H. (2013) A Note on a Two-Warehouse Inventory Model for Deteriorating Items with Varying Quadratic Demand under Conditionally Permissible Delay in Payment. Journal of the Orissa Mathematical Society, 32, 32-59.

[27] Singh, T. and Pattanayak, H. (2014) An EOQ Inventory Model for Deteriorating 
Items with Quadratic Demand and Partial Backlogging. Journal of the Orissa Mathematical Society, 33, 109-123.

[28] Goyal, S.K. (1985) Economic Order Quantity under Conditions of Permissible Delay in Payments. Journal of the Operational Research Society, 36, 335-338. https://doi.org/10.1057/jors.1985.56

[29] Aggarwal, S.P. and Jaggi, C.K. (1995) Ordering Policies of Deteriorating Items under Permissible Delay in Payments. Journal of the Operational Research Society, 36, 658-662. https://doi.org/10.1057/jors.1995.90

[30] Musa, A. and Sani, B. (2012) Inventory Ordering Policies of Delayed Deteriorating Items under Permissible Delay in Payments. International Journal of Production Economics, 136, 75-83. https://doi.org/10.1016/j.ijpe.2011.09.013

[31] Chen, S.-C., Cárdenas-Barrón, L.E. and Teng, J.T. (2014) Retailer's Economic Order Quantity When the Supplier Offers Conditionally Permissible Delay in Payments Link to Order Quantity. International Journal of Production Economics, 155, 284-291. https://doi.org/10.1016/j.ijpe.2013.05.032

[32] Singh, T., Sahoo, N.C. and Sahoo, C.K. (2016) An EOQ Model for Deteriorating Items with Inventory Dependent Demand and Initial Order Quantity Dependent Deterioration. International Journal of Management Concepts and Philosophy, 9, 306-329. https://doi.org/10.1504/IJMCP.2016.079840

[33] Jaggi, C.K. and Aggarwal, S.P. (1996) EOQ Model for Deteriorating Items with Salvage Values. Bulletin of Pure and Applied Science, 15, 67-71.

[34] Mishra, P. and Shah, N.H. (2008) Inventory Management of Time Dependent Deteriorating Items with Salvage Value. Applied Mathematical Sciences, 16, 793-798.

[35] Annadurai, K. (2013) An Optimal Replenishment Policy for Decaying Items with Shortages and Salvage Value. International Journal of Management Science and Engineering Management, 8, 38-46. https://doi.org/10.1080/17509653.2013.783188

[36] Mishra, U. and Tripathy, C.K. (2015) An Inventory Model for Weibull Deteriorating Items with Salvage Value. International Journal of Logistics Systems and Management, 22, 67-76. https://doi.org/10.1504/IJLSM.2015.070896 


\section{Notations}

The following symbols are needed for developing the mathematical model:

$I(t)$ : Instantaneous inventory level at any time $t \geq 0$.

$R(t)$ : Time-varying quadratic demand rate, where $R(t)=a+b t+c t^{2}$ where $a>0, b \neq 0$ and $c \neq 0$.

$\theta:$ Constant deterioration rate.

$h_{1}$ : Inventory holding cost excluding interest charges, \$/unit/year.

$C_{2}$ : Unit purchase cost, \$/unit.

$C_{3}$ : Ordering cost of the inventory per cycle, $\$$ /order.

$I_{c}$ : Interest charged, \$/year.

$I_{e}:$ Interest earned, \$/year.

$t_{p}$ : Purchaser's permissible delay period offered by the supplier for settling the account.

$I_{o}:$ Size of the initial inventory.

$I_{o}^{*}$ : Optimal quantity.

$T$ : Length of the cycle time (decision variable).

$T^{*}$ : Optimal value of $T$.

$T V C_{A}(T)$ : Total inventory cost per unit time for $t_{p}<T$.

$T V C_{B}(T)$ : Total inventory cost per unit time for $t_{p}>T$.

$T V C(T)$ : Optimal cost, which is a function of time. 